07,01

\title{
Влияние отжига на микроструктуру и механические свойства ультрамелкозернистого технически чистого Al
}

\author{
() А.М. Мавлютов ${ }^{1}$, Т.А. Латынина ${ }^{1,2}$, М.Ю. Мурашкин ${ }^{3,4}$, Р.3. Валиев ${ }^{3,4}$, T.С. Орлова ${ }^{1,2, q}$ \\ ${ }^{1}$ Санкт-Петербургский национальный исследовательский университет \\ информационных технологий, механики и оптики, \\ Санкт-Петербург, Россия \\ ${ }^{2}$ Физико-технический институт им. А.Ф. Иофрфе РАН, \\ Санкт-Петербург, Россия \\ ${ }^{3}$ Санкт-Петербургский государственный университет, \\ Санкт-Петербург, Россия \\ ${ }^{4}$ Уфримский государственный авиационный технический университет, \\ Институт фризики перспективных материалов, \\ Уфра, Россия \\ ฯ E-mail: orlova.t@mail.ioffe.ru
}

(Поступила в Редакцию 27 марта 2017 г.)

Исследовано влияние отжига на микроструктуру и механические свойства ультрамелкозернистого (УМЗ) технически чистого $\mathrm{Al}$, предварительно подвергнутого интенсивной пластической деформации кручением под давлением. Установлено, что отжиг УМЗ-образцов в диапазоне температур 363-473 К в течение $1 \mathrm{~h}$ приводит к повышению условного предела текучести и предела прочности, прирост которых достигает максимального значения (до 50 и 30\% соответственно) после отжига при $423 \mathrm{~K}$. Обсуждается ключевая роль неравновесных большеугловых границ зерен в полученном эффекте упрочнения УМЗ-А1 путем отжига. Увеличение прочности сопровождается значительным снижением пластичности. Предложен новый подход для улучшения пластичности УМЗ-Al при сохранении высокого уровня прочности. Он заключается во введении дополнительной плотности дислокаций в релаксированную отжигом УМЗ-структуру.

Авторы (М.Ю.М. и Р.З.В.) выражают благодарность Министерству образования и науки РФ за финансовую поддержку в рамках проекта № 14.Б25.31.0017.

Рентгеноструктурные исследования проведены с использованием оборудования Ресурсного центра научного парка СПбГУ „Рентгенодифракционные методы исследования“.

DOI: 10.21883 /FTT.2017.10.44964.094

\section{1. Введение}

Сплавы на основе алюминия являются перспективными материалами для электротехнических приложений благодаря таким свойствам, как высокая электропроводность, коррозионная стойкость, высокая пластичность и легкость вследствие относительно низкой плотности. В ряде случаев сочетание высокой прочности и пластичности является необходимым условием для практического применения алюминиевых сплавов. В последние годы были проведены исследования влияния интенсивной пластической деформации (ИПД) на механические свойства Al и сплавов на его основе [1-10]. Было показано, что ИПД приводит к повышению прочности и микротвердости за счет измельчения зерен до ультрамелкого масштаба и повышения плотности дефектов кристаллической решетки $[1,2,5-8]$, а также за счет формирования особой структуры границ зерен (ГЗ) [1]. Существенным недостатком ультрамелкозернистой (УМЗ) структуры является значительное снижение пластичности по сравнению с пластичностью в крупнозернистом (КЗ) состоянии [6]. Для оптимизации прочностных и пластических свойств в последнее время активно проводятся исследования влияния отжига на механические свойства Al [11-16]. Однако результаты этих исследований достаточно противоречивы. Так, в ряде работ наблюдалось повышение прочности УМЗ-материалов при отжиге [11-14]. Например, в работе [11] обнаружено повышение прочности в результате отжига при $423 \mathrm{~K}$ высокочистого (99.99 wt.\%) и технически чистого (99.2 wt.\%) Al, предварительно обработанных специальной прокаткой (accumulative roll-bonding). Авторы связывают повышение прочности с уменьшением источников подвижных дислокаций за счет их стока в процессе отжига в близкостоящие большеугловые границы зерен (БУГЗ) [11]. В работе [14] показано, что отжиг при 423 К УМЗ-образцов технически чистого Al, подвергнутого интенсивной пластической деформации кручением (ИПДК), приводит к повышению микротвердости на $13 \%$. В работе [15] исследован технически чистый $\mathrm{Al}(99.5$ wt.\%), в котором УМЗ-структура получена ротационной ковкой, и показано, что последующий отжиг при температурах до $448 \mathrm{~K}$ не приводит к изменению микротвердости. Противоречивость имеющихся в научной литературе данных по влиянию отжига на прочность алюминия, по-видимому, связана с особенностями УМЗ-структур, полученных разными методами и режимами ИПД. 
В связи с этим важной задачей представляется выявление ключевых микроструктурных параметров, ответственных за упрочнение УМЗ-Аl при отжиге, а также действующих в этом случае механизмов упрочнения. В настоящей работе проведены детальные исследования изменения прочности и пластичности в корреляции с эволюцией микроструктуры в результате отжига технически чистого Al (99.5 wt.\%), предварительно подвергнутого ИПДК. Показано, что отжиг УМЗ-Al при температурах $363-473 \mathrm{~K}$ в течение $1 \mathrm{~h}$ приводит к значительному повышению условного предела текучести и предела прочности, что связано с уменьшением источников подвижных дислокаций в результате релаксации дислокационной структуры неравновесных БУГЗ в процессе отжига. Впервые показано, что небольшая дополнительная деформация УМЗ-Аl после отжига при $423 \mathrm{~K}$ позволяет значительно (до уровня К3-Al) повысить его пластичность при сохранении высокого уровня прочности, что наиболее вероятно связано с введением дополнительных подвижных дислокаций. Это открывает новый подход для одновременного повышения прочности и пластичности УМЗ-металлов.

\section{2. Образцы и экспериментальные методики}

В работе исследовались образцы технически чистого Al (99.5 wt.\%). Из исходного прутка, имеющего К3-структуру, были вырезаны заготовки в виде цилиндров диаметром $9 \mathrm{~mm}$ и высотой $8 \mathrm{~mm}$. Далее заготовки были обработаны ИПДК с помощью пресса Walter Klement $\mathrm{GmbH}$ НРТ-07. ИПДК-обработка на десять оборотов $(n=10)$ была проведена при комнатной температуре (КТ) под давлением $6 \mathrm{GPa}[1,5]$. В результате ИПДК обработки получились диски диаметром $20 \mathrm{~mm}$ и толщиной $1.5 \mathrm{~mm}$, степень истинной деформации в области на расстоянии $5 \mathrm{~mm}$ от центра диска составила $e \approx 6.6[5]$.

Затем был проведен отжиг образцов при различных температурах из интервала $363-673 \mathrm{~K}$ в течение $1 \mathrm{~h}$. Далее образцы после ИПДК-обработки и без последующего отжига обозначены как Al_RT, а образцы после ИПДК и последующего отжига - как Al_ $T_{\text {an }}$, где $T_{\text {an }}$ - температура отжига в К. Исходный КЗ-образец обозначен как Al_CG (CG - coarse-grained).

Подробный анализ микроструктуры полученных образцов был проведен нами ранее [14,17], основные параметры микроструктуры, такие как средний размер зерна и распределение границ зерен по разориентировкам, представлены в табл. 1. Как видно из этой таблицы, в результате ИПДК-обработки в образцах сформировалась УМЗ-структура преимущественно с БУГЗ $\left(f_{>15} \approx 77 \%\right)$ со средним размером зерна $\sim 810 \mathrm{~nm}$, отжиг при температурах до $473 \mathrm{~K}$ не приводит к существенному росту зерна и изменению разориентировок ГЗ, однако в структуре происходят процессы возврата, о чем свидетельствует снижение плотности дислокаций $[14,17]$.
Таблица 1. Параметры микроструктуры образцов Al после ИПДК-обработки и последующего отжига по данным работы [14]

\begin{tabular}{c|c|c|c}
\hline Образец & $d_{a v}, \mathrm{~nm}$ & $f_{\leq 15}, \%$ & $f_{>15}, \%$ \\
\hline $\mathrm{Al} \_\mathrm{RT}$ & $810 \pm 9$ & 23 & 77 \\
$\mathrm{Al}$ 363 & $850 \pm 11$ & 22 & 78 \\
$\mathrm{Al}$ 403 & $1130 \pm 17$ & 20 & 80 \\
$\mathrm{Al} 423$ & $1160 \pm 9$ & 24 & 76 \\
$\mathrm{Al} 473$ & $1090 \pm 18$ & 28 & 72 \\
$\mathrm{Al} \_673$ & $7200 \pm 525$ & 69 & 31
\end{tabular}

Примечание. $d_{\mathrm{av}}-$ средний размер зерен, $f \leq 15-$ доля малоугловых границ зерен, $f_{>15}$ - доля большеугловых границ зерен с разориентацией $\leq 15$ и $>15^{\circ}$ соответственно.

В работе был проведен ряд дополнительных структурных исследований методами рентгеноструктурного анализа (РСА) и растровой электронной микроскопии.

PCA проводился на дифрактометре Bruker D8 DISCOVER в режиме симметричного $\theta-2 \theta$-сканирования с использованием параллельного пучка излучения $\mathrm{Cu} K_{\alpha}(40 \mathrm{kV}, 40 \mathrm{~mA})$. Шаг сканирования составил $\Delta 2 \theta=0.02^{\circ}$, а время экспозиции - $0.5 \mathrm{~s}$. Полнопрофильным моделированием методом Паули с использованием программного обеспечения „TOPAS 5.0“ определялись средний размер областей когерентного рассеяния $C$ и уровень микроискажений кристаллической решетки $\left\langle\varepsilon^{2}\right\rangle^{1 / 2}$. На основе данных РСА определялась плотность дислокаций по формуле [18]

$$
L_{\mathrm{dis}}=\frac{2 \sqrt{3}\left\langle\varepsilon^{2}\right\rangle^{1 / 2}}{C b},
$$

где $b-$ вектор Бюргерса.

Анализ поверхности изломов разрушенных образцов проводился на сканирующем электронном микроскопе JSM-6490LV (JEOL) при ускоряющем напряжении $20 \mathrm{kV}$.

Для проведения механических испытаний из полученных в результате ИПДК-обработки дисков на электроэрозионном станке были вырезаны образцы в виде

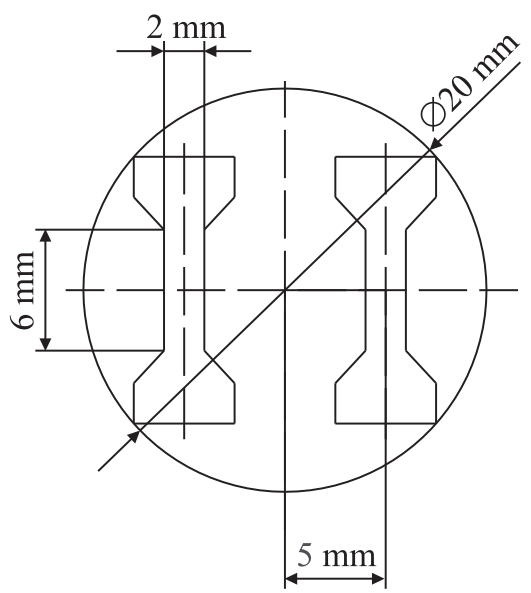

Рис. 1. Схема вырезки образцов для испытаний на растяжение. 
Таблица 2. Механические свойства образцов $\mathrm{Al}$ после ИПДК-обработки и отжига

\begin{tabular}{|c|c|c|c|c|}
\hline Образец & $\sigma_{0.2}, \mathrm{MPa}$ & $\sigma_{\mathrm{UTS}}, \mathrm{MPa}$ & $\delta, \%$ & $\delta_{1}, \%$ \\
\hline Al_CG & 33 & 46 & 38 & 29 \\
\hline Al_RT & 135 & 184 & 18 & 2 \\
\hline $\mathrm{Al} \_363$ & 184 & 223 & 14 & 2 \\
\hline Al_403 & 185 & 222 & 9 & 1 \\
\hline Al_423 & 201 & 237 & 1 & 0.5 \\
\hline $\mathrm{Al} \_473$ & 203 & 207 & 1 & 0.5 \\
\hline Al_673 & 28 & 55 & 42 & 26 \\
\hline $\mathrm{Al} \_423+0.25$ & 130 & 180 & 34 & 19 \\
\hline $\mathrm{Al} \_423+0.25+423$ & 202 & 231 & 13 & 1 \\
\hline $\mathrm{Al} \_423+0.25+423+0.25$ & 125 & 167 & 41 & 23 \\
\hline $\mathrm{Al} \_423+0.25+423+0.25+423$ & 205 & 221 & 18 & 1 \\
\hline
\end{tabular}

Примечание. Приведены средние значения условного предела текучести $\sigma_{0.2}$, предела прочности $\sigma_{\mathrm{UTS}}$, относительного удлинения до разрушения $\delta$, относительного равномерного удлинения $\delta_{1}$.

лопаток с шириной рабочей части $2 \mathrm{~mm}$ и длиной $6 \mathrm{~mm}$. Схема вырезки и конфигурация образцов представлены на рис. 1. Испытания образцов на одноосное растяжение были проведены на машине Shimadzu AG-XD Plus c постоянной скоростью деформации $5 \cdot 10^{-4} \mathrm{~s}^{-1}$. Деформация образцов регистрировалась с помощью видеоэкстензометра TRViewX 55S. Для каждого состояния было испытано, как минимум, по четыре образца. На основе полученных диаграмм напряжение-деформация были определены условный предел текучести $\sigma_{0.2}$, соответствующий $0.2 \%$ деформации, предел прочности $\sigma_{\mathrm{UTS}}$, относительное удлинение до разрушения $\delta$ и относительное равномерное удлинение $\delta_{1}$ образца.

\section{3. Экспериментальные результаты и их обсуждение}

На рис. 2 представлены диаграммы напряжениедеформация образцов $\mathrm{Al}$ в исходном КЗ-состоянии, в

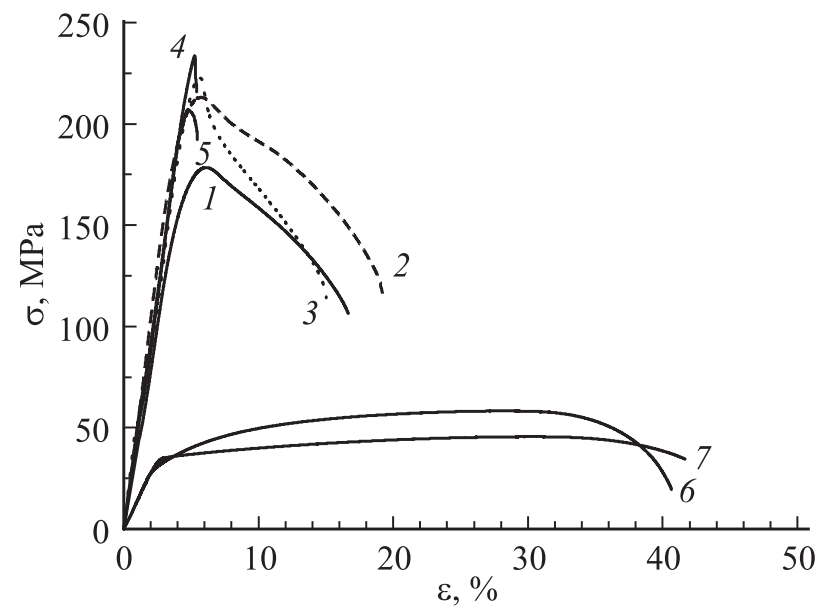

Pис. 2. Диаграммы напряжение-деформация образцов $\mathrm{Al}$ после ИПДК-обработки на 10 оборотов при КТ (1), после последующего отжига при температурах 363 (2), 403 (3), 423 (4), $473(5)$ и $673 \mathrm{~K}(6)$, а также в исходном КЗ-состоянии (7).

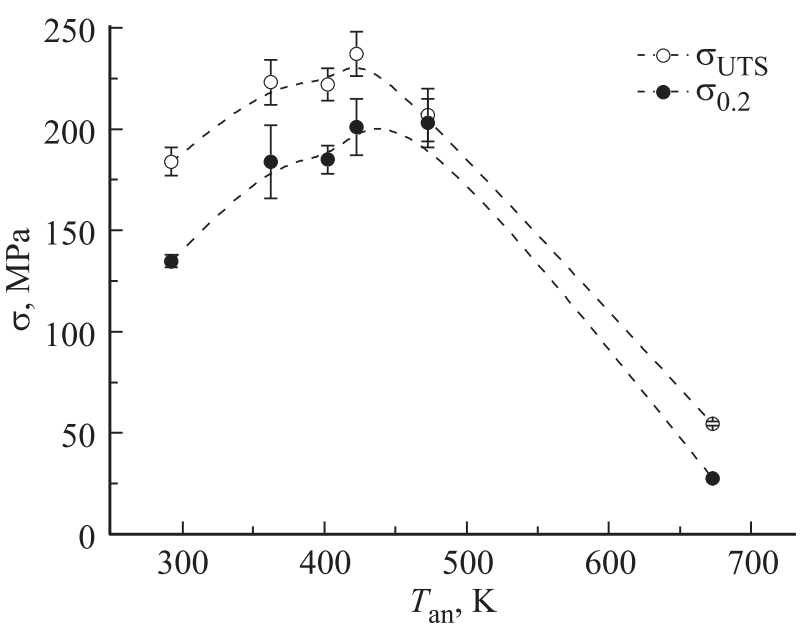

Рис. 3. Зависимости условного предела текучести $\sigma_{0.2}$ и предела прочности $\sigma_{\text {UTS }}$ образцов УМЗ-Al от температуры отжига.

УМЗ-состоянии, полученном ИПДК-обработкой, а также после различных отжигов УМЗ-состояния. В исходном К3-состоянии образцы Al_CG демонстрируют довольно низкий условный предел текучести $\sigma_{0.2} \approx 33 \mathrm{MPa}$, низкую предельную прочность $\sigma_{\mathrm{UTS}} \approx 46 \mathrm{MPa}$ и высокую пластичность до разрушения $\delta \approx 38 \%$. В результате ИПДК-обработки наблюдается повышение предела прочности и условного предела текучести в $\sim 4$ раза, однако пластичность образцов снижается до $\delta \approx 18 \%$. Данные результаты хорошо согласуются с результатами работ [2-4,11-13,15], в которых ИПД образцов Al была выполнена другими методами, такими, например как специальная прокатка (accumulative roll-bonding), ротационная ковка, равноканальное угловое прессование. В соответствии с соотношением Холла-Петча $[19,20]$ высокие показатели условного предела текучести образцов Al_RT связаны с измельчением зерен в результате ИПДК-обработки и, как следствие, увеличения объемной плотности ГЗ в структуре. Вклад в упрочнение также вносит увеличение плотности дислокаций 


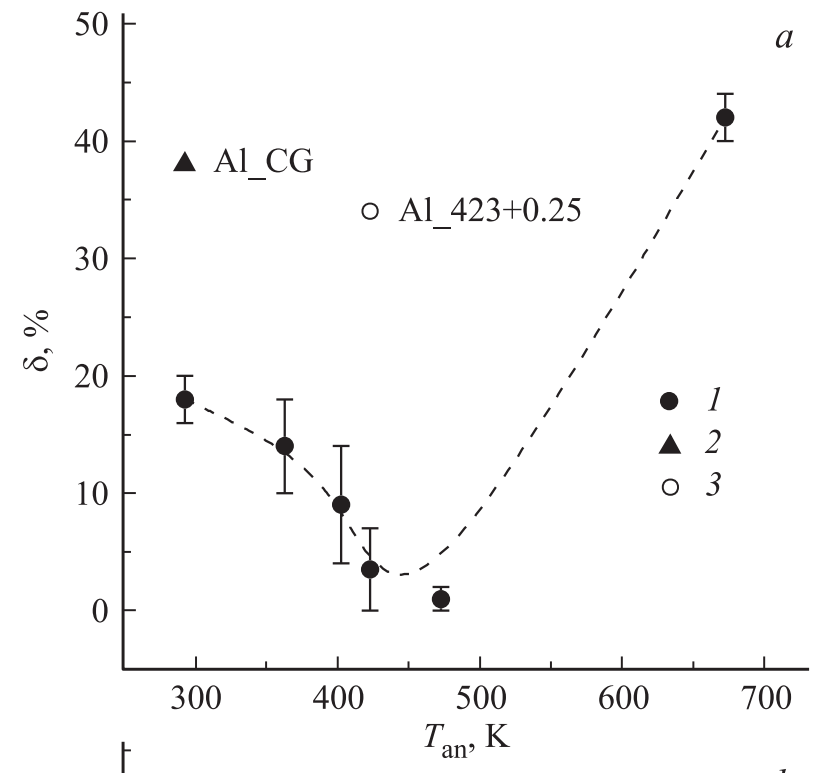

$b$

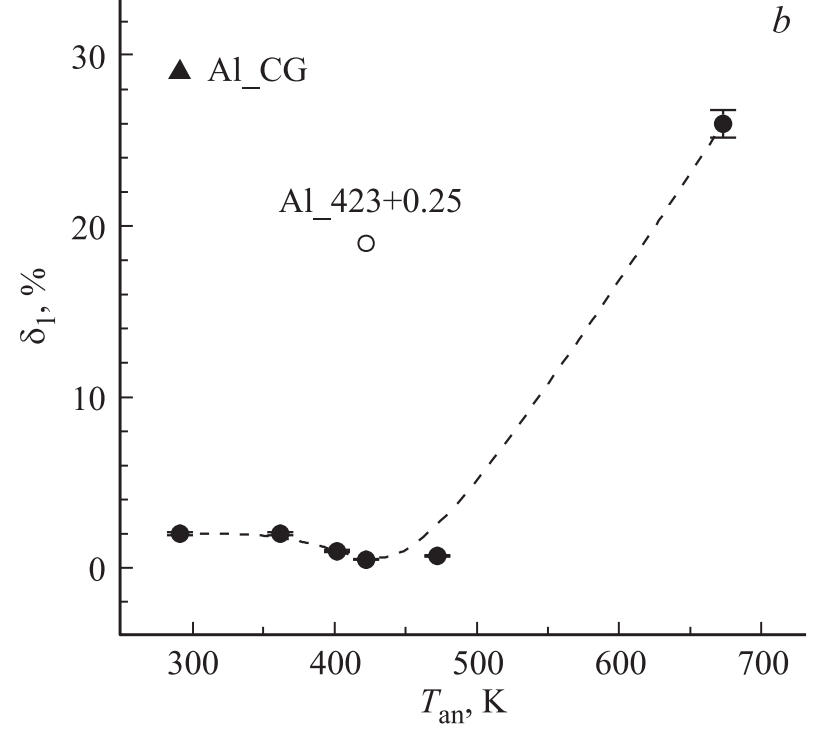

Рис. 4. Изменение относительного удлинения до разрушения $(a)$ и относительного удлинения до начала разупрочнения $(b)$ образцов УМЗ-А1 в зависимости от температуры отжига (1). 2 - исходное КЗ-состояние, 3 - состояние Al_ $423+0.25$.

в результате ИПД [1,3,6-8]. Последующие отжиги при температурах $363-473 \mathrm{~K}$ приводят к дополнительному повышению предела прочности и условного предела текучести до 30 и $50 \%$ соответственно (рис. 3 ), однако пластичность образцов значительно снижается (рис. 4). Подробные данные испытаний на растяжение приведены в табл. 2. Отметим, что максимальное повышение прочности получено после отжига при $423 \mathrm{~K}$, при котором пластичность падает до минимального значения $\delta \approx 1 \%$. Данное состояние было выбрано для дальнейшего исследования.

На рис. 5 представлены результаты исследования поверхности разрушения образцов $\mathrm{Al}$ методом сканирующей электронной микроскопии. Образец Al_CG продемонстрировал очень высокую степень относительного сужения (рис. 5, $a$ ) и характерный для вязкого материала ямочный излом (рис. $5, b$ ): глубокие ямки, наличие и развитость бороздок на боковых поверхностях ямок (рис. $5, b$, вставка) являются показателем высокой пластичности образцов [21].

Для образцов $\mathrm{Al}$, подвергнутых ИПДК (образцы Al_RT), разрушение происходило при небольшом относительном сужении (рис. $5, c$ ), при этом на изломах наблюдалось большое количество малых по протяженности и глубине ямок (рис. $5, d$ ), что характерно для прочного материала с относительно невысокой пластичностью [21]. Образец $\mathrm{Al} 4223$ продемонстрировал разрушение с очень низким относительным сужением (рис. $5, e$ ) и как следствие самую короткую стадию локализованной деформации (кривая 4 на рис. 2 и рис. $4, b$ ) среди изученных образцов. Следует отметить, что в данном образце существует много зон с малоразвитым рельефом, которые расположены достаточно однородно по поверхности (рис. 5,e). Сотовый рельеф поверхности излома у образца $\mathrm{Al} \_423$, представляющий собой мелкие равноосные неглубокие ямки (рис. $5, f)$, является признаком практически хрупкого разрушения [21].

Как показали проведенные нами ранее $[14,17]$ исследования микроструктуры, в результате отжига образцов Al_RT, имеющих УМЗ-структуру, происходит снижение плотности дислокаций. Более того, ранее [17] методом просвечивающей электронной микроскопии нами было показано, что измеренные методом РСА плотности дислокаций относятся главным образом к ГЗ и прилегающим областям, а в теле зерен дислокации практически отсутствуют. При низкотемпературном отжиге $(363-403 \mathrm{~K})$ понижение плотности дислокаций происходит, по-видимому, главным образом за счет перестройки структуры ГЗ из неравновесной в более равновесную [17]. Такая перестройка структуры ГЗ может быть причиной повышения предела текучести и одновременного снижения пластичности образцов после отжигов. Действительно, после ИПДК ГЗ являются источниками упругих искажений решетки и как следствие локальных внутренних упругих напряжений [17]. После соответствующего низкотемпературного отжига ГЗ релаксируют в более равновесное состояние, уменьшая при этом поля упругих напряжений [17]. Поэтому для того чтобы дислокации из ГЗ начали скольжение в образце $\mathrm{Al} \_423$, необходимо повысить в нем уровень напряжения по сравнению с пределом текучести образца Al_RT. По-видимому, низкая пластичность объясняется тем, что количество источников подвижных дислокаций после отжига сильно уменьшается. Уменьшение количества источников дислокаций после низкотемпературного отжига образцов технически чистого Al (99.2 wt.\%), предварительно обработанных специальной прокаткой (accumulative roll-bonding) на большую степень деформации $e=4.8$, отмечалось ранее в работе [11]. Авторы [11] полагают, что уменьшение количества источников дислокаций происходит в результате стока подвижных внутризеренных дислокаций в близкостоящие БУГЗ, которые преобладают в УМЗ-структуре этих образцов. Это 
$a$
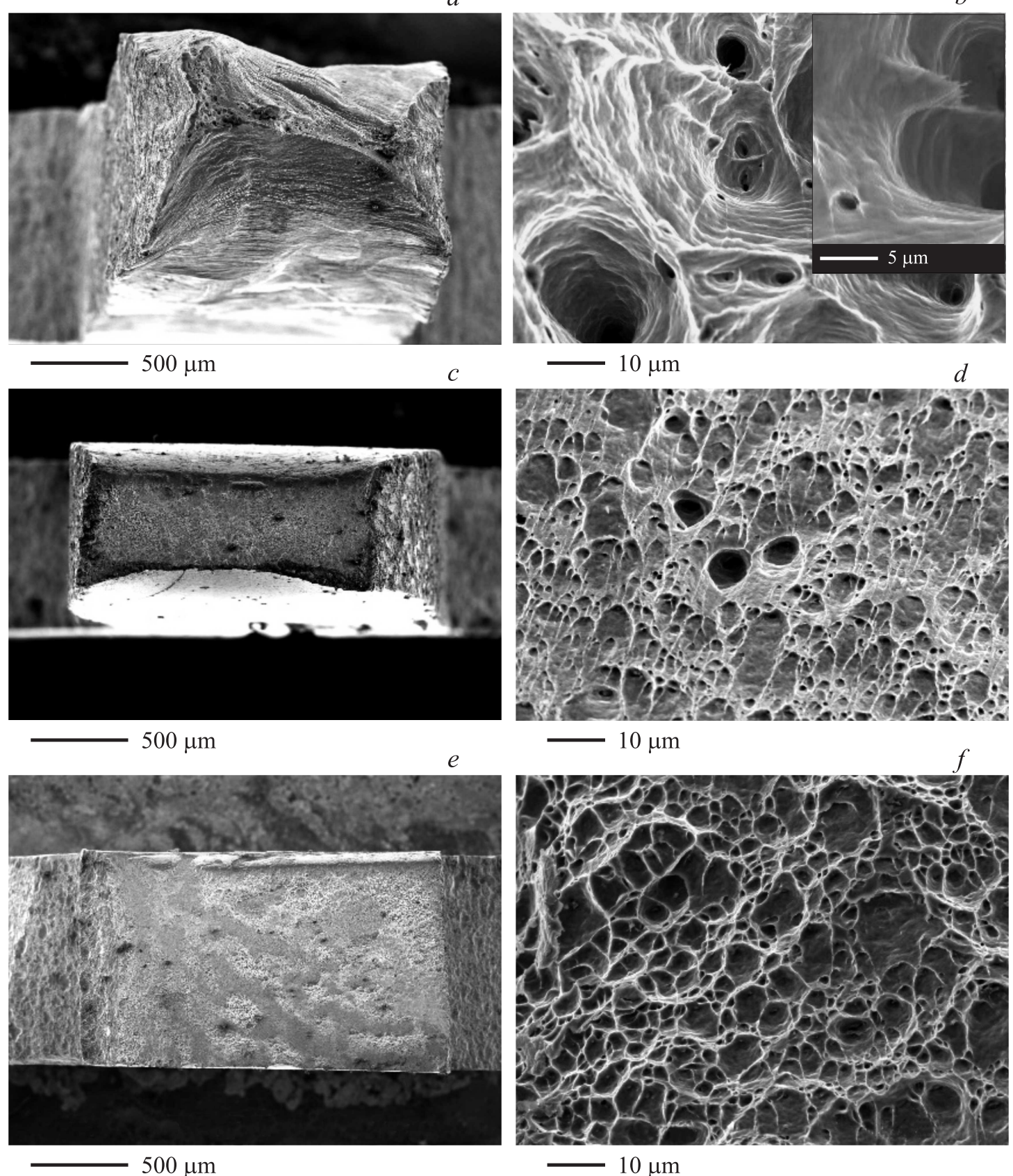

$500 \mu \mathrm{m}$

Рис. 5. Данные сканирующей электронной микроскопии. Фрактография образцов $\mathrm{Al}: a, b-$ в исходном КЗ-состоянии; $c, d-$ после ИПДК-обработки на 10 оборотов при КТ, $e, f$ - после отжига УМЗ-образцов при $423 \mathrm{~K}$ в течение $1 \mathrm{~h}$.

объясняет увеличение предела текучести и одновременное падение пластичности у структурированного такой деформацией $\mathrm{Al}[11]$. В наших образцах $\mathrm{Al}$, структурированных ИПДК, также наблюдается преобладающее количество БУГЗ ( 77\%), однако количество внутризеренных дислокаций пренебрежимо мало [17]. Как отмечалось выше, основной структурной перестройкой при низкотемпературном отжиге (363-403 K) в данном случае является перестройка структуры ГЗ из неравновесной в более равновесную. Доминирующее количество БУГЗ, по-видимому, является обязательным условием для достижения упрочнения УМЗ-Al путем низкотемпературного отжига. Действительно, в работе [15], в которой не наблюдался эффект упрочнения УМЗ-Al отжигом, большинство ГЗ - малоугловые границы. Полученные в нашей работе результаты свидетельствуют также в пользу того, что неравновесность БУГЗ в УМЗ-структуре, полученной ИПДК, играет существенную роль для проявления эффекта упрочнения при отжиге. Вероятно, релаксация БУГЗ может происходить за счет аннигиляции в них подвижных внутризеренных дислокаций или за счет перестройки зернограничной 
Таблица 3. Результаты рентгеноструктурного анализа образцов $\mathrm{Al}$ после ИПДК-обработки и отжига

\begin{tabular}{l|c|r|c}
\hline \multicolumn{1}{c|}{ Образец } & $C, \mathrm{~nm}$ & \multicolumn{1}{c|}{$\left\langle\varepsilon^{2}\right\rangle^{1 / 2}, \%$} & $L_{\mathrm{dis}}, \mathrm{m}^{-2}$ \\
\hline Al_RT & $240 \pm 40$ & $0.008 \pm 0.003$ & $\sim 4.1 \cdot 10^{12}$ \\
Al_423 & $250 \pm 50$ & $0.003 \pm 0.003$ & $\sim 1.5 \cdot 10^{12}$ \\
Al_423+0.25 & $300 \pm 60$ & $0.01 \pm 0.003$ & $\sim 4.1 \cdot 10^{12}$
\end{tabular}

Примечание. $C$ - средний размер областей когерентного рассеяния, $\left\langle\varepsilon^{2}\right\rangle^{1 / 2}-$ уровень микроискажений кристаллической решетки, $L_{\text {dis }}$ - плотность дислокаций.

дислокационной структуры, что приводит к уменьшению внутренних упругих напряжений от границ зерен и уменьшению источников подвижных дислокаций.

Образцы Al_423 продемонстрировали наилучшие прочностные характеристики $\left(\sigma_{0.2} \approx 201 \mathrm{MPa}\right.$ и $\left.\sigma_{\mathrm{UTS}} \approx 237 \mathrm{MPa}\right)$, однако при этом пластичность упала до минимальных значений $\delta \approx 1 \%$. С целью увеличения пластичности была предпринята попытка введения новых дислокаций в отожженные образцы $\mathrm{Al} 423$ путем их дополнительной обработки ИПДК на четверть оборота $(n=0.25)$ при КТ (образец Al_423+0.25). Как было показано ранее для сплава системы $\mathrm{Al}-\mathrm{Mg}-\mathrm{Si}$ [9], в результате такой небольшой дополнительной деформации значительно (в 2 раза) повышалась плотность дислокаций, при этом остальные параметры микроструктуры (размер зерна, размер и распределение вторичных фаз и т.д.) образцов сохранялись. В нашей работе был проведен РСА с определением плотности дислокаций в образцах до отжига (Al_RT), после отжига $(\mathrm{Al}$ 423) и после дополнительной деформации отожженного образца на четверть оборота $\left(\mathrm{Al} \_423+0.25\right)$. Результаты РСА приведены в табл. 3. Как и отмечалось ранее, отжиг приводит к значительному понижению плотности дислокаций (приблизительно в 2.7 раза). Последующая небольшая дополнительная деформация, как и ожидалось, обеспечила значительное повышение плотности дислокаций (практически до уровня, характерного для неотожженной УМЗ-структуры).

Образцы Al_423+0.25 также были испытаны на одноосное растяжение. Типичная диаграмма растяжения образца Al_423+0.25 показана на рис. 6 (кривая 4.1). Видно, что дополнительная деформация кручением на $n=0.25$ оборота привела к значительному увеличению пластичности до $\delta \approx 34 \%$, при этом уровень прочностных свойств (значения $\sigma_{0.2}$ и $\sigma_{\mathrm{UTS}}$ ) хотя и уменьшился по сравнению с образцом Al_423 (кривая 4 на рис. 6), но сохранился на уровне, характерном для образца Al_RT (кривая 1 на рис. 6), структурированного ИПДК.

Рассмотрим более детально диаграмму растяжения образца Al_423+0.25 (кривая 4.1 на рис. 6). На ней можно выделить три участка. На участке I происходит упрочнение материала до достижения 7\% деформации. Далее на участке II наблюдается незначительное разупрочнение, практически на этом участке кривой образец деформируется почти при постоянном напряжении до достижения деформации $\delta_{1} \approx 19 \%$. На участке III происходит существенное разупрочнение, свидетельствующее о локализации деформации, а при достижении деформации $\delta \approx 34 \%$ - разрушение образца. По-видимому, введенные дополнительной деформацией дислокации могут начать свое скольжение при напряжениях значительно более низких, чем значения $\sigma_{0.2}$, характерные для образ-

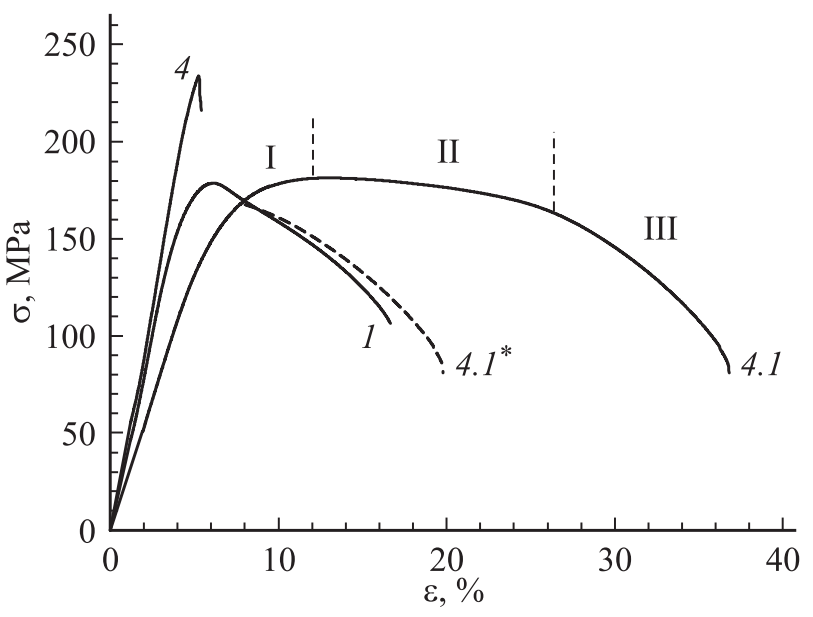

Pис. 6. Диаграммы напряжение-деформация для образцов Al. 1 - после ИПДК-обработки на 10 оборотов при КТ, 4 - после ИПДК-обработки и отжига при $423 \mathrm{~K}$. Кривая 4.1 - обработка, аналогичная обработке для кривой 4 , плюс ИПДК-обработка на 0.25 оборота при КТ, кривая $4.1^{*}$ - участок III кривой 4.1, сдвинутый для сравнения с кривой 1 . Номера кривых 1,4 соответствуют приведенным на рис. 2.

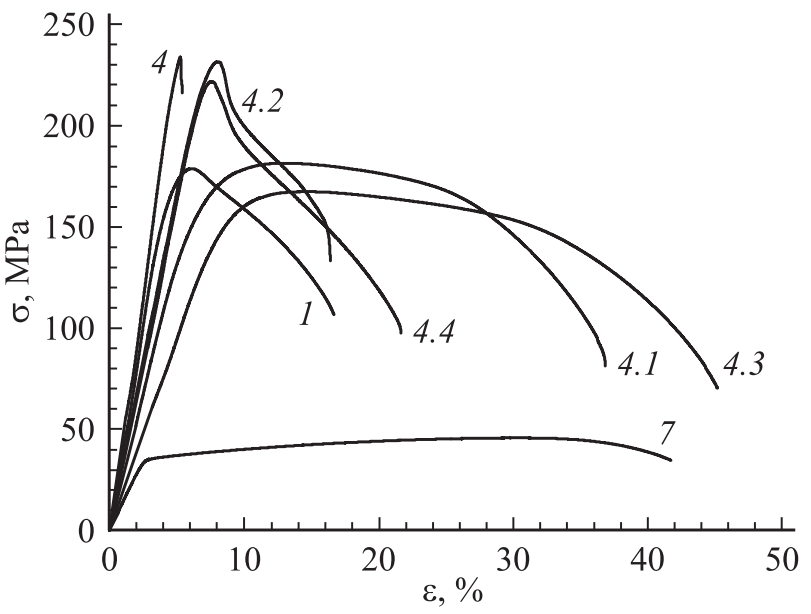

Рис. 7. Диаграммы напряжение-деформация для образцов $\mathrm{Al}$. 1 - после ИПДК-обработки на 10 оборотов при КТ, 4 - после ИПДК-обработки и отжига при $423 \mathrm{~K}$. Кривая 4.1 - обработка, аналогичная обработке для кривой 4 , плюс ИПДК-обработка на 0.25 оборота при КТ, кривая 4.2 - та же обработка, что для 4.1 , плюс отжиг при $423 \mathrm{~K}$ в течение $1 \mathrm{~h}$, кривая 4.3 - та же обработка, что для 4.2, плюс ИПДК-обработка на 0.25 оборота при КТ, кривая 4.4 - та же обработка, что для 4.3 , плюс отжиг при $423 \mathrm{~K}$ в течение $1 \mathrm{~h}$. Кривая $7-$ исходное КЗ-состояние. Номера кривых 1,4,7 соответствуют приведенным на рис. 2. 
цов $\mathrm{Al} \_423$, и сравнимых с $\sigma_{0.2} \approx 135 \mathrm{MPa}$ для образца $\mathrm{Al} \_\mathrm{RT}$. Стадия II, происходящая при почти постоянном значении деформирующего напряжения, вероятно, связана с относительно однородным пластическим течением в большом количестве зон образца до того, как происходит стадия локализации деформации (стадия III), завершающаяся разрушением. Примечательно, что участок III на кривой деформации образца $\mathrm{Al} \_423+0.25$ фактически идентичен стадии разупрочнения у образца Al_RT (кривая 4.1* на рис. 6).

Далее образцы Al_423 + 0.25 были вновь подвергнуты отжигу при $423 \mathrm{~K}$ в течение $1 \mathrm{~h}$ (образец обозначен как Al_423+0.25+423), а затем вновь обработаны ИПДК на 0.25 оборота при КТ (образец Al_423 $+0.25+423+0.25)$ и снова отожжены при $423 \mathrm{~K}$ в течение 1 h (образец Al_423 $+0.25+423+0.25+423$ ). После каждого этапа обработки были проведены испытания на растяжение, результаты которых приведены на рис. 7 и в табл. 2. Как видно из рис. 7 и табл. 2, каждый этап обработки ИПДК на 0.25 оборота при КТ приводил к существенному увеличению пластичности образцов с УМЗ-структурой (кривые 4.1 и 4.3 на рис. 7), при этом условный предел текучести и предел прочности сохранялись на высоком уровне, соизмеримом с соответствующими значениями в образцах Al_RT (табл. 2). Отжиг при $423 \mathrm{~K}$ на каждом этапе приводил к повышению прочности и снижению пластичности (кривые 4.2 и 4.4 на рис. 7, табл. 2). Таким образом, дополнительная термомеханическая обработка, состоящая из серии отжигов и дополнительных деформаций, позволила повысить пластичность до уровня, характерного для исходного КЗ-образца, и даже несколько превысить его, достигнув значения $\delta \approx 41 \%$ (кривая 4.3 на рис. 7), при этом значения предела текучести и предела прочности $\left(\sigma_{0.2} \approx 125 \mathrm{MPa}\right.$ и $\sigma_{\mathrm{UTS}} \approx 167 \mathrm{MPa}$ соответственно $)$ были соизмеримы с подобными характеристиками для УМЗ-Al после ИПДК (образец Al_RT). Насколько нам известно, одновременное достижение таких высоких значений прочности и пластичности получено для технически чистого $\mathrm{Al}$ впервые. Возможно, что предложенный в работе подход для одновременного увеличения прочности и пластичности будет эффективным и в случае других металлических материалов.

\section{4. Заключение}

Обнаружено значительное повышение предела текучести (до 50\%) и предела прочности (до $30 \%$ ) для УМЗ-Al, структурированного методом ИПДК, при отжиге в интервале температур $363-473 \mathrm{~K}$ в течение $1 \mathrm{~h}$, что указывает на существование особого механизма упрочнения в УМЗ-структуре, ключевую роль в котором наиболее вероятно играют неравновесные большеугловые границы зерен.

Впервые достигнуто одновременное увеличение прочности (в $\sim 3.6$ раза) и пластичности (до $\sim 42 \%$ ) технически чистого Al. С этой целью обработка исходных КЗ-образцов была проведена в несколько этапов, включающих ИПДК на 10 оборотов при КТ, отжиг УМЗ-образцов в интервале температур 363-673 К и дополнительную ИПДК-обработку на 0.25 оборота при КТ. Показано, что такая дополнительная термомеханическая обработка УМЗ-Al позволяет существенно повысить пластичность материала при сохранении высоких значений предела текучести и предела прочности за счет введения в структуру дополнительных дислокаций.

\section{Список литературы}

[1] R.Z. Valiev, R.K. Islamgaliev, I.V. Alexandrov. Prog. Mater. Sci. 45, 103 (2000).

[2] H. Miyamoto, K. Ota, T. Mimaki. Scripta Mater. 54, 1721 (2006).

[3] E.A. El-Danaf, M.S. Soliman, A.A. Almajid, M.M. El-Rayes. Mater. Sci. Eng. A 458, 226 (2007).

[4] B. Talebanpour, R. Ebrahimi, K. Janghorban. Mater. Sci. Eng. A 527, 141 (2009).

[5] A.P. Zhilyaev, T.G. Langdon. Prog. Mater. Sci. 53, 893 (2008).

[6] I. Sabirov, M.Yu. Murashkin, R.Z. Valiev. Mater. Sci. Eng. A 560, 1 (2013).

[7] R.Z. Valiev, M.Yu. Murashkin, I. Sabirov. Scripta Mater. 76, 13 (2014).

[8] R. Reihanian, R. Ebrahimi, N. Tsuji, M.M. Moshksar. Mater. Sci. Eng. A 473, 189 (2008).

[9] А.М. Мавлютов, И.А. Касаткин, М.Ю. Мурашкин, Р.3. Валиев, Т.С. Орлова. ФТТ 57, 1998 (2015).

[10] M. Montazeri-Pour, M.H. Parsa, H.R. Jafarian, S. Taieban. Mater. Sci. Eng. A 639, 705 (2015).

[11] X. Huang, N. Hansen, N. Tsuji. Science 312, 249 (2006).

[12] N. Kamikawa, X. Huang, N. Tsuji, N. Hansen. Acta Mater. 57, 4198 (2009).

[13] Б.Н. Семенов, И.В. Смирнов, Ю.В. Судьенков, Н.В. Татаринова. ФММ 24, 319 (2015).

[14] A.M. Mavlyutov, A.S. Bondarenko, M.Yu. Murashkin, E.V. Boltynjuk, R.Z. Valiev, T.S. Orlova. J. Alloys Compd. 698, 539 (2017).

[15] M.A. Abdulstaar, E.A. El-Danaf, N.S. Waluyo, L. Wagner. Mater. Sci. Eng. A 565, 351 (2013).

[16] Y. Cao, L. He, Y. Zhou, P. Wang, J. Cui. Mater. Sci. Eng. A 674, 193 (2016).

[17] T.S. Orlova, A.M. Mavlyutov, A.S. Bondarenko, I.A. Kasatkin, M.Yu. Murashkin, R.Z. Valiev. Phil. Mag. 96, 2429 (2016).

[18] G.K. Williamson, R.E. Smallman. Phil. Mag. 1, 34 (1956).

[19] E.O. Hall. Proc. Phys. Soc. B 64, 747 (1951).

[20] N.J. Petch. J. Iron. Steel Inst. 174, 25 (1953).

[21] Т.А. Гордеева, И.П. Жегина. Анализ изломов при оценке надежности материалов. Машиностроение, М. (1978). $200 \mathrm{c}$. 